\title{
Intact parathyroid hormone value on the first postoperative day following total thyroidectomy as a predictor of permanent hypoparathyroidism: a retrospective analysis on 426 consecutive patients
}

\author{
Gian Luigi Canu' ${ }^{1}$ Fabio Medas ${ }^{1}$, Federico Cappellacci', Cristina Soddu', Giorgio Romano ${ }^{2}$, \\ Enrico Erdas ${ }^{1}$, Pietro Giorgio Calò ${ }^{1}$ \\ ${ }^{1}$ Department of Surgical Sciences, University of Cagliari, "Policlinico Universitario Duilio Casula", Monserrato, Italy \\ ${ }^{2}$ Department of Surgical, Oncological and Oral Sciences, Section of General and Urgent Surgery, University of Palermo, Palermo, Italy
}

\begin{abstract}
Introduction: Hypoparathyroidism represents a common complication following total thyroidectomy. To date, there is still no reliable and immediate postoperative parameter to establish which patients with postsurgical hypoparathyroidism will develop permanent hypoparathyroidism.

The main purpose of the present study was to assess whether the intact parathyroid hormone (iPTH) value on the first postoperative day is a good predictor of permanent hypoparathyroidism.

Material and methods: Patients undergoing thyroidectomy in our unit between March 2018 and January 2020 were analysed. According to the iPTH value on the first postoperative day and on the basis of the detection threshold of the iPTH test used, patients were divided into two groups: Group A (iPTH $\geq 4.6 \mathrm{pg} / \mathrm{mL}$ ) and Group B (iPTH $<4.6 \mathrm{pg} / \mathrm{mL}$, undetectable).

Results: In total 426 patients were included: 364 in Group A and 62 in Group B. Permanent hypoparathyroidism occurred in $3(0.82 \%)$ patients from Group A and in $26(41.94 \%)$ from Group B ( $p<0.001)$. When iPTH levels were $<4.6 \mathrm{pg} / \mathrm{mL}$ on the first postoperative day the sensitivity for the prediction of permanent hypoparathyroidism was $89.66 \%$, the specificity was $90.93 \%$, the positive predictive value (PPV) was $41.94 \%$, the negative predictive value (NPV) was $99.18 \%$ and the accuracy was $90.85 \%$.

Conclusions: An iPTH value $<4.6 \mathrm{pg} / \mathrm{mL}$ on the first postoperative day following total thyroidectomy has proven to be a good parameter for early identification of patients at high risk for permanent hypoparathyroidism. Moreover, we want to underline that in our experience no patient with an iPTH level $>6.5 \mathrm{pg} / \mathrm{mL}$ developed this complication. (Endokrynol Pol 2022; 73 (1): 49-55)
\end{abstract}

Key words: thyroidectomy; permanent hypoparathyroidism; complications; intact parathyroid hormone

\section{Introduction}

Thyroidectomy represents the most performed operation in endocrine surgery.

Hypoparathyroidism (HypoPT) represents a quite common complication following total thyroidectomy (TT) [1-10].

In most cases HypoPT reverses spontaneously within a few months; however, in some patients, it can persist. To date, there is a lack of international consensus concerning the time after thyroidectomy necessary to diagnose permanent hypoparathyroidism; for some authors 6 months are enough, while others extend this time period to 1 year [11-13].

The incidence of transient and permanent HypoPT is $6.9-46 \%$ and up to $14.5 \%$, respectively $[2,4,9,10]$.

Consequences of permanent HypoPT are represented by some severe conditions, such as kidney stones, nephrocalcinosis, chronic kidney disease, basal ganglia calcifications, myocardial dysfunction, dental abnormalities, and cataracts [9, 14-18].

In the case of permanent HypoPT, to avoid subtle but potentially lethal complications, long-term treatment, which consists of administration of calcium and vitamin $\mathrm{D}$, and careful follow-up are mandatory. However, it is important to underline that long-term calcium supplementation may cause side effects, such as myocardial infarction, gastrointestinal reactions, and urinary calculi $[9,19,20]$.

Costs to society due to this complication, in terms of medical treatments and surveillance, are considerable [1-10]. Moreover, permanent HypoPT is an important cause of medical litigation [21].

To date, there is still no reliable and immediate postoperative parameter to establish which patients with postsurgical HypoPT will develop permanent HypoPT [1, 
2,5-13]. Early identification of patients at high risk for the development of this condition would allow clinicians to provide patients with tailored information regarding the future and to plan an adequate follow-up after surgery.

The main purpose of the present study was to assess whether the intact parathyroid hormone (iPTH) value on the first postoperative day is a good predictor of permanent HypoPT.

\section{Material and methods}

\section{Study design}

This is a retrospective cohort study on patients who underwent thyroidectomy in our Unit of General and Endocrine Surgery (University of Cagliari) between March 2018 and January 2020. Patients were identified from a prospectively maintained institutional database.

We included only patients submitted to total thyroidectomy with or without lateral and/or central neck dissection, while those who underwent lobohystmectomy, completion thyroidectomy (following diagnosis of high-risk thyroid cancer after lobohystmectomy or for recurrent thyroid disease), simultaneous parathyroidectomy, and those with incomplete data were excluded from this study. According to the iPTH value on the first postoperative day and based on the detection threshold of the iPTH test used, patients were divided into two groups: those with $\mathrm{iPTH} \geq 4.6 \mathrm{pg} / \mathrm{mL}$ were included in Group A, while those with iPTH $<4.6 \mathrm{pg} / \mathrm{mL}$ (undetectable) were included in Group B.

Demographic data (sex, age), BMI value, information on the surgical procedure (extent of surgery, execution of parathyroid autotransplantation, volume of surgeons, rate of retrosternal goitre, and operative time), histological findings (thyroid weight, histopathological diagnosis), postoperative stay, and complications (recurrent laryngeal nerve injury, hypoparathyroidism, cervical haematoma, wound infection) were reported.

\section{Endpoints}

The primary endpoint was to evaluate the correlation between $\mathrm{iPTH}<4.6 \mathrm{pg} / \mathrm{mL}$ on the first postoperative day and the development of permanent hypoparathyroidism.

The secondary endpoints were to assess the risk factors for a drop in the iPTH value on the first postoperative day below $4.6 \mathrm{pg} / \mathrm{mL}$ and to compare the postoperative stay between the two groups.

\section{Information on the surgical procedure}

All operations were performed under general anaesthesia. Lateral and/or central neck dissection was performed in patients with preoperative diagnosis or intraoperative suspicion of lymph node metastases. Parathyroid glands and recurrent laryngeal nerves were systematically searched and identified. Devascularized or accidentally removed parathyroid glands were cut into small pieces approximately $1 \mathrm{~mm}^{3}$ in volume and autotransplanted into the sternocleidomastoid muscle. In order to facilitate recurrent laryngeal nerve identification and to confirm its functional integrity, intraoperative nerve monitoring (IONM) was almost always used. Haemostasis was mainly achieved by means of energy-based devices. One or two closed suction drains were systematically placed below the strap muscles. The duration of the surgical procedure was estimated in minutes from skin incision to skin closure. Retrosternal goitre was defined as a thyroid in which any part of the gland extended below the thoracic inlet with the patient in the surgical position.

\section{Postoperative management}

Serum calcium and $\mathrm{PTTH}$ values were assayed pre- and postoperatively. Intact parathyroid hormone was measured with ADVIA Cen- taur ${ }^{\circledast}$ XT Immunoassay Systems (Siemens Healthcare Diagnostics, Inc.). The detection threshold of the iPTH test used is equal to 4.6 $\mathrm{pg} / \mathrm{mL}$ (iPTH levels $<4.6 \mathrm{pg} / \mathrm{mL}$ are undetectable). Postsurgical hypoparathyroidism was defined as iPTH $<10 \mathrm{pg} / \mathrm{mL}$ following the operation (normal range $=10-65 \mathrm{pg} / \mathrm{mL}$ ).

All patients with postsurgical hypoparathyroidism, even if asymptomatic, received treatment with calcium carbonate (1-3 g/day) and calcitriol (0.5-1.5 $\mu \mathrm{g} /$ day). In cases of severe hypocalcaemia, intravenous calcium gluconate was used.

Permanent hypoparathyroidism was defined as iPTH levels below the normal range for more than 12 months.

A fibrolaryngoscopy was performed to assess vocal cord mobility in the case of suspected recurrent laryngeal nerve injury.

\section{Statistical analysis}

Statistical analyses were performed with MedCalc ${ }^{\circledast}$ 19.1.3. Chisquared test or Fisher exact test were used for categorical variables, which were described as counts and percentages, and t-test for continuous variables, which were expressed as means and standard deviations. Sensitivity, specificity, positive predictive value (PPV), negative predictive value (NPV), and accuracy were calculated. $p$ values $<0.05$ were considered statistically significant.

\section{Results}

A total of 426 patients were included in this study: 364 in Group A and 62 in Group B.

Results regarding the entire sample are reported in Tables 1 and 2, while findings and a comparison relating to the two groups are shown in Tables 3 and 4 .

No statistically significant difference was found between the two groups in terms of demographic data, BMI value, extent of surgery, execution of parathyroid autotransplantation, volume of surgeons, and histological findings.

Conversely, the rate of retrosternal goitre, mean operative time, and postoperative stay were significantly greater in Group B than in Group A ( $p=0.014$, $\mathrm{p}=0.001$, and $\mathrm{p}<0.001$, respectively).

Transient hypoparathyroidism occurred in 36 $(9.89 \%)$ patients in Group A and in $36(58.06 \%)$ in Group B ( $p<0.001)$, while there were $3(0.82 \%)$ cases of permanent hypoparathyroidism in Group A and $26(41.94 \%)$ in Group B ( $p<0.001)$. Patients in Group A who developed permanent hypoparathyroidism had an iPTH value on the first postoperative day equal to $4.7,5.0$, and $6.5 \mathrm{pg} / \mathrm{mL}$, respectively.

As reported in Table 5, when iPTH levels were $<4.6$ $\mathrm{pg} / \mathrm{mL}$ on the first postoperative day the sensitivity for the prediction of permanent hypoparathyroidism was $89.66 \%$, the specificity was $90.93 \%$, the PPV was $41.94 \%$, the NPV was $99.18 \%$, and the accuracy was $90.85 \%$.

\section{Discussion}

Even in the most experienced hands and despite progress in surgical technique, postsurgical HypoPT after total thyroidectomy remains a challenging problem, 
Table 1. Demographic data, body mass index (BMI) value, information on the surgical procedure, postoperative stay, and histological findings

\begin{tabular}{lc}
\hline & Total $(\mathbf{n}=426)$ \\
\hline Sex & $117(27.46 \%)$ \\
Male & $309(72.54 \%)$ \\
Female & $54.29 \pm 14.60$ \\
\hline Age [years] & \\
Mean \pm SD & $26.10 \pm 5.09$ \\
\hline BMl $\left[\mathrm{kg} / \mathrm{m}^{2}\right]$ & \\
\hline Mean $\pm \mathrm{SD}$ & \\
\hline
\end{tabular}

\begin{tabular}{lc}
\hline Extent of surgery & $384(90.13 \%)$ \\
$\mathrm{TT}$ & $14(3.29 \%)$ \\
$\mathrm{TT}+\mathrm{ICND}$ & $16(3.76 \%)$ \\
$\mathrm{TT}+\mathrm{CND}$ & $12(2.82 \%)$ \\
$\mathrm{TT}+\mathrm{CND}+\mathrm{LND}$ & $7(1.64 \%)$ \\
\hline Parathyroid autotransplantation & \\
\hline Volume of surgeons* & \\
$<15$ & $40(9.39 \%)$ \\
$15-29$ & $39(9.15 \%)$ \\
$30-60$ & $63(14.79 \%)$ \\
$>60$ & $284(66.67 \%)$ \\
\hline Retrosternal goitre & $99(23.24 \%)$ \\
\hline Operative time [min] & $98.48 \pm 30.95$ \\
Mean \pm SD & \\
\hline Postoperative stay [days] & $3.06 \pm 1.82$ \\
Mean \pm SD & \\
\hline Thyroid weight [g] & $52.30 \pm 52.50$ \\
Mean \pm SD & $196(15.49 \%)$ \\
\hline Histological diagnosis & $129.81 \%)$ \\
Graves' disease & \\
Autoimmune thyroiditis & \\
Malignancy & \\
\hline & \\
\hline
\end{tabular}

SD — standard deviation; TT — total thyroidectomy; ICND — ipsilateral central neck dissection; CND — central neck dissection; LND — lateral neck dissection *Thyroidectomies per year

and permanent HypoPT represents the most common long-term complication following this procedure [1-10].

During this operation parathyroid glands may be damaged due to various mechanisms: vascular injury (interrupted blood flow or impaired venous efflux), mechanical or thermal stress, and involuntary removal [5, 9, 22-26].

Most authors, including us, claim that systematic research and identification of the parathyroid glands during thyroidectomy help to reduce the occurrence of parathyroid injury. The number of glands identified during surgery and left in situ is considered para-
Table 2. Complications

\begin{tabular}{lc}
\hline & Total $(\mathbf{n}=\mathbf{4 2 6})$ \\
\hline Unilateral recurrent nerve injury & $17(3.99 \%)$ \\
\hline Bilateral recurrent nerve injury & $4(0.94 \%)$ \\
\hline Cervical haematoma & $9(2.11 \%)$ \\
\hline Transient hypoparathyroidism & $72(16.90 \%)$ \\
\hline Permanent hypoparathyroidism & $29(6.81 \%)$ \\
\hline Wound infection & $4(0.94 \%)$ \\
\hline
\end{tabular}

mount to prevent postsurgical hypoparathyroidism $[9,22,24,27]$.

Many authors advise carefully inspection of the surgical specimen surface for inadvertently removed parathyroid glands, and if present, they recommend autotransplantation into the sternocleidomastoid muscle. Autotransplantation can also be performed in the case of detection of accidentally devascularised parathyroid glands $[9,28]$.

An increased risk of developing permanent HypoPT has been associated with several factors: female sex, long duration of thyroid disease before surgery, autoimmune thyroiditis, Graves' disease, thyroid cancer, high thyroid weight, low postoperative PTH and calcium values, long duration of surgery, retrosternal goitre, lack of surgeon experience, and central neck dissection [1, 9, 23-42]. Another important risk factor for this complication is represented by reoperations for recurrent thyroid disease. These operations are complex due to the presence of scar tissue that causes a distortion of the surgical field, making accurate identification of the anatomical structures quite difficult $[27,43,44]$.

The main aim of our study was to assess whether the iPTH value on the first postoperative day is a good predictor of permanent HypoPT. In particular, we evaluated the correlation between iPTH $<4.6 \mathrm{pg} / \mathrm{mL}$ and the development of this complication. Moreover, as secondary endpoints, we assessed the risk factors for a drop in the iPTH value below $4.6 \mathrm{pg} / \mathrm{mL}$ and compared the postoperative stay between patients with $\mathrm{iPTH} \geq 4.6 \mathrm{pg} / \mathrm{mL}$ (Group A) and those with iPTH $<4.6$ $\mathrm{pg} / \mathrm{mL}$ (Group B).

When iPTH concentrations were $<4.6 \mathrm{pg} / \mathrm{mL}$ the sensitivity, the specificity, the negative predictive value, and the accuracy for the prediction of permanent hypoparathyroidism were high $(89.66 \%, 90.93 \%, 99.18 \%$, and $90.85 \%$, respectively), but also the positive predictive value was quite good $(41.94 \%)$.

The occurrence of permanent hypoparathyroidism was statistically significantly greater in Group B. In Group A, among patients who developed permanent 
Table 3. Comparison between Group A (with iPTH level $\geq 4.6 \mathrm{pg} / \mathrm{mL}$ on the first postoperative day) and Group B (with iPTH level $\leq 4.6 \mathrm{pg} / \mathrm{mL}$ on the first postoperative day)

\begin{tabular}{|c|c|c|c|}
\hline & $\begin{array}{c}\text { Group A } \\
(n=364)\end{array}$ & $\begin{array}{l}\text { Group B } \\
(\mathrm{n}=62)\end{array}$ & p value \\
\hline \multicolumn{4}{|l|}{ Sex } \\
\hline Male & $99(27.20 \%)$ & $18(29.03 \%)$ & \multirow{2}{*}{0.765} \\
\hline Female & $265(72.80 \%)$ & $44(70.97 \%)$ & \\
\hline Age [years] & \multirow{2}{*}{$54.23 \pm 14.75$} & \multirow[b]{2}{*}{$54.65 \pm 13.80$} & \multirow{2}{*}{0.837} \\
\hline Mean \pm SD & & & \\
\hline $\mathrm{BMI}\left[\mathrm{kg} / \mathrm{m}^{2}\right]$ & \multirow{2}{*}{$25.96 \pm 4.98$} & \multirow{2}{*}{$26.92 \pm 5.67$} & \multirow{2}{*}{0.171} \\
\hline Mean \pm SD & & & \\
\hline \multicolumn{4}{|l|}{ Extent of surgery } \\
\hline TT & $332(91.21 \%)$ & $52(83.87 \%)$ & \multirow{4}{*}{0.283} \\
\hline TT + ICND & $10(2.75 \%)$ & $4(6.45 \%)$ & \\
\hline $\mathrm{TT}+\mathrm{CND}$ & $13(3.57 \%)$ & $3(4.84 \%)$ & \\
\hline $\mathrm{TT}+\mathrm{CND}+\mathrm{LND}$ & $9(2.47 \%)$ & $3(4.84 \%)$ & \\
\hline Parathyroid autotransplantation & $5(1.37 \%)$ & $2(3.23 \%)$ & 0.271 \\
\hline \multicolumn{4}{|l|}{ Volume of surgeons* } \\
\hline$<15$ & $32(8.79 \%)$ & $8(12.90 \%)$ & \multirow{4}{*}{0.777} \\
\hline $15-29$ & $34(9.34 \%)$ & $5(8.06 \%)$ & \\
\hline $30-60$ & $54(14.84 \%)$ & $9(14.52 \%)$ & \\
\hline$>60$ & $244(67.03 \%)$ & $40(64.52 \%)$ & \\
\hline Retrosternal goitre & 77 (21.15\%) & $22(35.48 \%)$ & 0.014 \\
\hline Operative time [min] & \multirow{2}{*}{$96.47 \pm 30.23$} & \multirow{2}{*}{$110.32 \pm 32.74$} & \multirow{2}{*}{0.001} \\
\hline Mean \pm SD & & & \\
\hline Postoperative stay [days] & \multirow{2}{*}{$2.93 \pm 1.60$} & \multirow{2}{*}{$3.85 \pm 2.63$} & \multirow{2}{*}{$<0.001$} \\
\hline Mean \pm SD & & & \\
\hline Thyroid weight $[\mathrm{g}]$ & \multirow{2}{*}{$50.32 \pm 46.85$} & \multirow{2}{*}{$63.97 \pm 77.35$} & \multirow{2}{*}{0.058} \\
\hline Mean \pm SD & & & \\
\hline \multicolumn{4}{|l|}{ Histological diagnosis } \\
\hline Graves' disease & $55(15.11 \%)$ & $11(17.74 \%)$ & 0.596 \\
\hline Autoimmune thyroiditis & $111(30.49 \%)$ & $16(25.81 \%)$ & 0.456 \\
\hline Malignancy & $158(43.41 \%)$ & $32(51.61 \%)$ & 0.230 \\
\hline
\end{tabular}

SD — standard deviation; BMI — body mass index; TT — total thyroidectomy; ICND — ipsilateral central neck dissection; CND — central neck dissection; LND — lateral neck dissection; *Thyroidectomies per year

Table 4. Occurrence of hypoparathyroidism in Group A (with iPTH level $\geq 4.6 \mathrm{pg} / \mathrm{mL}$ on the first postoperative day) and Group B (with iPTH level $\leq 4.6 \mathrm{pg} / \mathrm{mL}$ on the first postoperative day)

\begin{tabular}{lccc}
\hline & $\begin{array}{c}\text { Group A } \\
(\mathbf{n = 3 6 4 )}\end{array}$ & $\begin{array}{c}\text { Group B } \\
(\mathbf{n = 6 2})\end{array}$ & p value \\
\hline Transient hypoparathyroidism & $36(9.89 \%)$ & $36(58.06 \%)$ & $<0.001$ \\
\hline Permanent hypoparathyroidism & $3(0.82 \%)$ & $26(41.94 \%)$ & $<0.001$ \\
\hline
\end{tabular}

hypoparathyroidism, the highest $\mathrm{PTH}$ value on the first postoperative day was $6.5 \mathrm{pg} / \mathrm{mL}$.

Regarding the comparison between the two groups, no statistically significant difference was found in terms of demographic data, BMI value, extent of surgery, execution of parathyroid autotransplantation, volume of surgeons, and histological findings. However, the rate of retrosternal goitre, mean operative time, and postoperative stay were significantly greater in Group B than in Group A. 
Table 5. Correlation between intact parathyroid hormone (iPTH) $<4.6 \mathrm{pg} / \mathrm{mL}$ on the first postoperative day and the development of permanent hypoparathyroidism

\begin{tabular}{ll}
\hline Sensitivity & $89.66 \%$ \\
\hline Specificity & $90.93 \%$ \\
\hline PPV & $41.94 \%$ \\
\hline NPV & $99.18 \%$ \\
\hline Accuracy & $90.85 \%$ \\
\hline
\end{tabular}

PPV — positive predictive value; NPV — negative predictive value

We performed a similar analysis about the same topic a few years ago [34]. In this previous study the iPTH value on the first postoperative day, according to which patients were divided into two groups, was $6.3 \mathrm{pg} / \mathrm{mL}$. This value was determined on the basis of the detection threshold of the iPTH test used during that period. The different detection threshold, compared with that of the present study, is due to the use of another type of reagent. In the previous experience, when the iPTH concentration was $<6.3 \mathrm{pg} / \mathrm{mL}$, the sensitivity and the negative predictive value for permanent HypoPT were high (both 100\%), but the specificity and the positive predictive value were poor $(18.03 \%$ and $21.88 \%$, respectively). In this case no patient with $\mathrm{PTH}$ values $\geq 6.3$ $\mathrm{pg} / \mathrm{mL}$ developed permanent hypoparathyroidism.

Carefully reviewing the data of the previous study, we found that among patients with $\mathrm{PTH} \geq 6.3 \mathrm{pg} / \mathrm{mL}$ the lowest PTH value was $6.6 \mathrm{pg} / \mathrm{mL}$. For this reason, we can affirm that, in our experience, no patient with an iPTH level $>6.5 \mathrm{pg} / \mathrm{mL}$ on the first postoperative day developed permanent hypoparathyroidism.

In the literature, there are some other similar studies that evaluated the correlation between the $\mathrm{iPTH}$ concentration on the first postoperative day and the development of permanent hypoparathyroidism [23, $28,35-40]$.

In the experience of Julián et al. [38], iPTH levels $\leq 5.8$ $\mathrm{pg} / \mathrm{mL}$ on the first postoperative day had $100 \%$ sensitivity, $81.5 \%$ specificity, and $30 \%$ positive predictive value for the prediction of permanent HypoPT. In this study, all patients with iPTH concentrations $>5.8 \mathrm{pg} / \mathrm{mL}$ had a normal parathyroid function in the long term.

Almquist et al. [28] affirmed that iPTH concentrations measured on the first postoperative day are associated with the risk of permanent HypoPT. In their experience, of 10 patients with permanent HypoPT, 8 had iPTH $<6.6 \mathrm{pg} / \mathrm{mL}$ and 2 had iPTH between 6.6 and $15 \mathrm{pg} / \mathrm{mL}$. However, among patients with iPTH values $<6.6 \mathrm{pg} / \mathrm{mL}$ the rate of this complication was only $19.2 \%$.

In the study of Wang et al. [23], iPTH values $<7$ $\mathrm{pg} / \mathrm{mL}$ on the first postoperative day had sensitivity and negative predictive value of $100 \%$ for the prediction of permanent HypoPT, while specificity and positive predictive value were, respectively, $70.19 \%$ and $8.63 \%$.

Kim et al. [37] stated that the safest cut-off value of iPTH on the first postoperative day for the prediction of permanent HypoPT is $9.65 \mathrm{pg} / \mathrm{mL}$ (70.9\% sensitivity and $100 \%$ specificity). None of the patients with iPTH $>9.65$ $\mathrm{pg} / \mathrm{mL}$ developed this complication.

In the study of Wang et al. [35], iPTH concentrations $\leq 3.14 \mathrm{pg} / \mathrm{mL}$ on the first postoperative day had $100 \%$ sensitivity for the prediction of permanent HypoPT, $95 \%$ specificity, $66.67 \%$ positive predictive value, and $100 \%$ negative predictive value. Thus, these authors affirmed that iPTH levels $>3.14 \mathrm{pg} / \mathrm{mL}$ are great in assessing the absence of this complication.

Calvo Espino et al. [36] found that a cut-off value of iPTH on the first postoperative day of $5 \mathrm{pg} / \mathrm{mL}$ has 95\% sensitivity, $77 \%$ specificity, $21.6 \%$ positive predictive value, and $99.6 \%$ negative predictive value for the prediction of permanent HypoPT. Thus, they stated that this iPTH level, because of its high negative predictive value, is a useful predictor of permanent HypoPT.

Godlewska et al. [39] affirmed that an iPTH concentration $<6 \mathrm{pg} / \mathrm{mL}$ on the first postoperative day represents an important risk factor for the development of permanent HypoPT, while an iPTH level > $6 \mathrm{pg} / \mathrm{mL}$ is always associated with full recovery of parathyroid glands function.

Zheng et al. [40] stated that the iPTH concentration measured on the first postoperative day following total thyroidectomy is closely related to the occurrence of permanent HypoPT and is an independent predictive risk factor. In particular, in patients with an iPTH value $\leq 5.51$ the sensitivity was $100 \%$, the specificity $85.1 \%$, the PPV $22 \%$, and the NPV $100 \%$.

Based on our results and those of other authors, a univocal iPTH value on the first postoperative day for the prediction of permanent HypoPT has not yet been identified.

Regarding the comparison between the two groups, in particular as regards the risk factors for a drop in the iPTH value on the first postoperative day below $4.6 \mathrm{pg} / \mathrm{mL}$, our findings in terms of rate of retrosternal goitre and operative times are in agreement with those reported in the literature [1, 9, 24-27, 29-33].

In contrast to what is described in the literature [1, 9, 24-27, 29-33, 42], no statistically significant difference was found in terms of sex, extent of surgery (execution of central neck dissection), volume of surgeons, thyroid weight, and histopathological diagnosis. This result may be due to the limited sample size, with particular reference to Group B, but also to the fact that ours is a high-volume centre for thyroid surgery. Regarding sample size, for example, the $\mathrm{p}$ value regarding 
thyroid weight was only slightly above the threshold for the declaration of statistical significance; probably with a greater sample the difference would have been statistically significant. As regards the second reason, it is widely demonstrated that high-volume centres have lower complication rates, in this case injury of parathyroid glands, even in the most challenging cases $[45,46]$. Moreover, regarding the volume of surgeons, it is important to underline that all the surgeons in our unit have broad experience, even if not as first operator, in the field of thyroid surgery.

With regard to parathyroid autotransplantation, we performed this procedure in too few cases to be able to evaluate with adequate statistical power its usefulness in avoiding the development of permanent hypoparathyroidism, as suggested by many authors $[9,28]$.

Regarding postoperative stay, as widely described in the literature [1-13,41], patients with lower postoperative PTH values and therefore lower postoperative serum calcium levels cannot, for safety reasons, be discharged early and therefore have a longer hospital stay.

Our present study has two main limitations.

First of all, it is a retrospective study based on a prospectively maintained institutional database. For this reason, it is lacking in some information, such as the number of parathyroid glands identified during surgery and left in situ or found at histopathological examination.

The second limitation is the limited sample size, with particular reference to Group B. This condition hinders the achievement of statistical power suitable for an accurate comparison of all the variables considered through univariate analysis. Moreover, for the same reason, adequate statistical power was not reached for the evaluation of risk factors for a drop in the $\mathrm{iPTH}$ value on the first postoperative day below $4.6 \mathrm{pg} / \mathrm{mL}$ through multivariate analysis (overall model fit: $\mathrm{p}=0.056$ ). The results of this analysis were therefore not reported in the paper. However, we want to underline that this evaluation represented only a secondary endpoint.

\section{Conclusions}

An iPTH value $<4.6 \mathrm{pg} / \mathrm{mL}$ on the first postoperative day following total thyroidectomy has proven to be a good parameter for early identification of patients at high risk for the development of permanent hypoparathyroidism. Moreover, we want to underline that in our experience, also considering the results of our previous study on this topic, no patient with an iPTH level $>6.5$ $\mathrm{pg} / \mathrm{mL}$ on the first postoperative day developed this complication.

Our findings are important to provide patients with tailored information regarding the future and to plan an adequate follow-up after surgery.
However, on the basis of our results and those of the other authors, a univocal $\mathrm{iPTH}$ value on the first postoperative day for the prediction of permanent HypoPT has not yet been identified. Thus, further studies are needed to better investigate this topic.

\section{Ethical approval}

All procedures performed in this study were in accordance with the 1964 Helsinki declaration and its later amendments. Ethical approval was obtained from the local ethics committee (Independent Ethics Committee, A.O.U. Cagliari). Written informed consent was obtained from all patients included in this study.

\section{Conflicts of interest}

The authors have no conflicts of interest to declare.

\section{Funding}

No funding to declare.

\section{Authors' contributions}

G.L.C.: Study conception, involved in drafting the manuscript; F.M.: Study conception, critical revision of the manuscript; F.C.: Acquisition of data, involved in drafting the manuscript; C.S. and G.R.: Analysis and interpretation of data; E.E.: Study design, literature search, involved in drafting the manuscript; P.G.C.: Study design, involved in drafting the manuscript and revising it critically for important intellectual content. All authors read and approved the final manuscript for publication.

\section{Acknowledgements}

We want to thank our other colleagues and our fabulous nursing staff for their precious collaboration and commitment in the management of patients.

\section{References}

1. Puzziello A, Rosato L, Innaro N, et al. Hypocalcemia following thyroid surgery: incidence and risk factors. A longitudinal multicenter study comprising 2,631 patients. Endocrine. 2014; 47(2): 537-542, doi: 10.1007/s12020-014-0209-y, indexed in Pubmed: 24563161.

2. Bilezikian JP, Khan A, Potts JT, et al. Hypoparathyroidism in the adult: epidemiology, diagnosis, pathophysiology, target-organ involvement, treatment, and challenges for future research. J Bone Miner Res. 2011; 26(10): 2317-2337, doi: 10.1002/jbmr.483, indexed in Pubmed: 21812031.

3. Asari R, Passler C, Kaczirek K, et al. Hypoparathyroidism after total thyroidectomy: a prospective study. Arch Surg. 2008; 143(2): 132-7; discussion 138, doi: 10.1001/archsurg.2007.55, indexed in Pubmed: 18283137.

4. Pattou F, Combemale F, Fabre S, et al. Hypocalcemia following thyroid surgery: incidence and prediction of outcome. World J Surg. 1998; 22(7): 718-724, doi: 10.1007/s002689900459, indexed in Pubmed: 9606288.

5. Zheng J, Song H, Cai S, et al. Evaluation of clinical significance and risk factors of incidental parathyroidectomy due to thyroidectomy: A single-center retrospective clinical study. Medicine (Baltimore). 2017; 96(39): e8175, doi: 10.1097/MD.0000000000008175, indexed in Pubmed: 28953673.

6. Coimbra C, Monteiro F, Oliveira P, et al. Hypoparathyroidism following thyroidectomy: Predictive factors. Acta Otorrinolaringol Esp. 2017; 68(2): 106-111, doi: 10.1016/j.otorri.2016.06.008, indexed in Pubmed: 27776803.

7. Kakava K, Tournis S, Papadakis G, et al. Postsurgical Hypoparathyroidism: A Systematic Review. In Vivo. 2016; 30(3): 171-179, indexed in Pubmed: 27107072. 
8. Cho JN, Park WS, Min SY. Predictors and risk factors of hypoparathyroidism after total thyroidectomy. Int J Surg. 2016; 34: 47-52, doi: 10.1016/j ijsu.2016.08.019, indexed in Pubmed: 27554178 .

9. Orloff LA, Wiseman SM, Bernet VJ, et al. American Thyroid Association Statement on Postoperative Hypoparathyroidism: Diagnosis, Prevention, and Management in Adults. Thyroid. 2018; 28(7): 830-841, doi: 10.1089/thy.2017.0309, indexed in Pubmed: 29848235.

10. Díez JJ, Anda E, Sastre J, et al. Permanent postoperative hypoparathyroidism: an analysis of prevalence and predictive factors for adequacy of control in a cohort of 260 patients. Gland Surg. 2020; 9(5): 1380-1388, doi: 10.21037/gs-20-288, indexed in Pubmed: 33224813.

11. Bollerslev J, Rejnmark L, Marcocci C, et al. European Society of Endocrinology. European Society of Endocrinology Clinical Guideline: Treatment of chronic hypoparathyroidism in adults. Eur J Endocrinol. 2015; 173(2): G1-20, doi: 10.1530/EJE-15-0628, indexed in Pubmed: 26160136.

12. Brandi ML, Bilezikian JP, Shoback D, et al. Management of Hypoparathyroidism: Summary Statement and Guidelines. J Clin Endocrino Metab. 2016; 101(6): 2273-2283, doi: 10.1210/jc.2015-3907, indexed in Pubmed: 26943719.

13. Stack BC, Bimston DN, Bodenner DL, et al. American Association Of Clinical Endocrinologists And American College Of Endocrinology disease state clinical review: postoperative hypoparathyroidism — definitions and management. Endocr Pract. 2015; 21(6): 674-685, doi: 10.4158/EP14462.DSC, indexed in Pubmed: 26135962

14. Lorente-Poch L, Sancho JJ, Carballo L, et al. Clinical profile and long-term follow-up of 32 patients with postoperative permanent hypoparathyroidism. Gland Surg. 2017; 6(Suppl 1): S3-SS10, doi: 10.21037/gs.2017.11.10, indexed in Pubmed: 29322017.

15. Mitchell DM, Regan S, Cooley MR, et al. Long-term follow-up of patients with hypoparathyroidism. J Clin Endocrinol Metab. 2012; 97(12): 4507-4514, doi: 10.1210/jc.2012-1808, indexed in Pubmed: 23043192

16. Rastogi R, Beauchamp NJ, Ladenson PW. Calcification of the basal ganglia in chronic hypoparathyroidism. J Clin Endocrinol Metab. 2003; 88(4): 1476-1477, doi: 10.1210/jc.2002-021804, indexed in Pubmed: 12679425.

17. Kinirons MJ, Glasgow JF. The chronology of dentinal defects related to medical findings in hypoparathyroidism. J Dent. 1985; 13(4): 346-349, doi: 10.1016/0300-5712(85)90032-6, indexed in Pubmed: 3866776.

18. Lorente-Poch L, Sancho JJ, Muñoz-Nova JL, et al. Defining the syndromes of parathyroid failure after total thyroidectomy. Gland Surg. 2015; 4(1): 82-90, doi: 10.3978/j.issn.2227-684X.2014.12.04, indexed in Pubmed: 25713783.

19. Khan MI, Waguespack SG, Hu MI. Medical management of postsurgical hypoparathyroidism. Endocr Pract. 2011; 17 Suppl 1: 18-25, doi: 10.4158/EP10302.RA, indexed in Pubmed: 21134871.

20. Reid IR, Bristow SM, Bolland MJ. Calcium supplements: benefits and risks. J Intern Med. 2015; 278(4): 354-368, doi: 10.1111/joim.12394, indexed in Pubmed: 26174589.

21. Polistena A, Di Lorenzo P, Sanguinetti A, et al. Medicolegal implications of surgical errors and complications in neck surgery: A review based on the Italian current legislation. Open Med (Wars). 2016; 11(1): 298-306, doi: 10.1515/med-2016-0058, indexed in Pubmed: 28352812.

22. Lorente-Poch L, Sancho JJ, Ruiz S, et al. Importance of in situ preservation of parathyroid glands during total thyroidectomy. Br J Surg. 2015 102(4): 359-367, doi: 10.1002/bjs.9676, indexed in Pubmed: 25605285.

23. Wang JB, Sun HL, Song CY, et al. Association between decreased serum parathyroid hormone after total thyroidectomy and persistent hypoparathyroidism. Med Sci Monit. 2015; 21: 1223-1231, doi: 10.12659/MSM.892867, indexed in Pubmed: 25923249.

24. Qasaimeh GR, Al Nemri S, Al Omari AK. Incidental extirpation of the parathyroid glands at thyroid surgery: risk factors and post-operative hypocalcemia. Eur Arch Otorhinolaryngol. 2011; 268(7): 1047-1051, doi: 10.1007/s00405-010-1413-x, indexed in Pubmed: 21132322.

25. Sitges-Serra A, Gallego-Otaegui L, Suárez S, et al. Inadvertent parathyroidectomy during total thyroidectomy and central neck dissection for papillary thyroid carcinoma. Surgery. 2017; 161(3): 712-719, doi: 10.1016/j.surg.2016.08.021, indexed in Pubmed: 27743717.

26. Imga $\mathrm{NN}$, Atas $\mathrm{H}$, Torgutalp $\mathrm{M}$, et al. Stratifying the risk factors for hypoparathyroidism after total thyroidectomy. A single Center study. Ann Ital Chir. 2019; 90: 21-30, indexed in Pubmed: 30862769.

27. Youssef T, Gaballah G, Abd-Elaal E, et al. Assessment of risk factors of incidental parathyroidectomy during thyroid surgery: a prospective study. Int J Surg. 2010; 8(3): 207-211, doi: 10.1016/j.ijsu.2009.12.008, indexed in Pubmed: 20060940.

28. Almquist M, Hallgrimsson P, Nordenström E, et al. Prediction of permanent hypoparathyroidism after total thyroidectomy. World J Surg.
2014; 38(10): 2613-2620, doi: 10.1007/s00268-014-2622-z, indexed in Pubmed: 24791907

29. Roh JL, Kim JM, Park CIl. Central lymph node metastasis of unilatera papillary thyroid carcinoma: patterns and factors predictive of nodal metastasis, morbidity, and recurrence. Ann Surg Oncol. 2011; 18(8): 2245-2250, doi: 10.1245/s10434-011-1600-z, indexed in Pubmed: 21327454

30. Hallorimsson P Nordenström E, Bergenfelz A, et al. Hypocalcaemia after total thyroidectomy for Graves' disease and for benign atoxic multinodular goitre. Langenbecks Arch Surg. 2012; 397(7): 1133-1137, doi: 10.1007/s00423-012-0981-1, indexed in Pubmed: 22976368.

31. Medas F, Erdas E, Canu GL, et al. Does hyperthyroidism worsen prognosis of thyroid carcinoma? A retrospective analysis on 2820 consecutive thyroidectomies. J Otolaryngol Head Neck Surg. 2018; 47(1): 6 doi: 10.1186/s40463-018-0254-2, indexed in Pubmed: 29357932.

32. Calò PG, Conzo G, Raffaelli M, et al. Total thyroidectomy alone versus ipsilateral versus bilateral prophylactic central neck dissection in clinically node-negative differentiated thyroid carcinoma. A retrospective multicenter study. Eur J Surg Oncol. 2017; 43(1): 126-132, doi: 10.1016/j. ejso.2016.09.017, indexed in Pubmed: 27780677

33. Pesce CE, Shiue Z, Tsai HL, et al. Postoperative hypocalcemia after thyroidectomy for Graves' disease. Thyroid. 2010; 20(11): 1279-1283, doi: 10.1089/thy.2010.0047, indexed in Pubmed: 20950255.

34. Canu GL, Medas F, Longheu A, et al. Correlation between iPTH Levels on the First Postoperative Day After Total Thyroidectomy and Permanent Hypoparathyroidism: Our Experience. Open Med (Wars). 2019 14: 437-442, doi: 10.1515/med-2019-0047, indexed in Pubmed: 31231683.

35. Wang W, Xia F, Meng C, et al. Prediction of permanent hypoparathyroidism by parathyroid hormone and serum calcium $24 \mathrm{~h}$ after thyroidectomy. Am J Otolaryngol. 2018; 39(6): 746-750, doi: 10.1016/j. amjoto.2018.08.005, indexed in Pubmed: 30197157.

36. Calvo Espino P Rivera Bautista JÁ, Artés Caselles M, et al Serum level of intact parathyroid hormone on the first day after total thyroidectomy as predictor of permanent hypoparathyroidism. Endocrinol Diabetes Nutr (Engl Ed). 2019; 66(3): 195-201, doi: 10.1016/j.endinu.2018.08.006, indexed in Pubmed: 30392997.

37. Kim H, Yu H, Bae I, et al. Prediction of Transient and Permanent Hypoparathyroidism after Total Thyroidectomy Using the Postoperative Serum Parathyroid Hormone Test: When Is the Best Time to Check? J Endocrin Surg. 2017; 17(3): 104, doi: 10.16956/jes.2017.17.3.104.

38. Julián MT, Balibrea JM, Granada ML, et al. Intact parathyroid hormone measurement at 24 hours after thyroid surgery as predictor of parathyroid function at long term. Am J Surg. 2013; 206(5): 783-789, doi: 10.1016/j. amjsurg.2013.01.038, indexed in Pubmed: 23835208.

39. Godlewska P, Benke M, Stachlewska-Nasfeter E, et al. Risk factors of permanent hypoparathyroidism after total thyroidectomy and central neck dissection for papillary thyroid cancer: a prospective study. Endokrynol Pol. 2020; 71(2): 126-133, doi: 10.5603/EP.a2020.0006, indexed in Pubmed: 32154569.

40. Zheng J, Cai S, Song H, et al. Measurement of serum intact parathyroid hormone concentration 1 day after total thyroidectomy to assess risk of permanent hypoparathyroidism. J Int Med Res. 2020 48(6): 300060520927199 , doi: $10.1177 / 0300060520927199$, indexed in Pubmed: 32527180

41. Lončar I, Dulfer RR, Massolt ET, et al. Postoperative parathyroid hormone levels as a predictor for persistent hypoparathyroidism. Eur J Endocrinol. 2020; 183(2): 149-159, doi: 10.1530/EJE-20-0116, indexed in Pubmed: 32580147.

42. Canu GL, Medas F, Conzo G, et al. Is prophylactic central neck dissection justified in patients with cN0 differentiated thyroid carcinoma? An overview of the most recent literature and latest guidelines. Ann Ital Chir. 2020; 91: 451-457, indexed in Pubmed: 33295306.

43. Medas F, Tuveri M, Canu GL, et al. Complications after reoperative thyroid surgery: retrospective evaluation of 152 consecutive cases. Updates Surg. 2019; 71(4): 705-710, doi: 10.1007/s13304-019-00647-y, indexed in Pubmed: 30937820.

44. Calò PG, Pisano G, Medas F, et al. Risk factors in reoperative thyroid surgery for recurrent goitre: our experience. G Chir. 2012; 33(10): 335-338, indexed in Pubmed: 23095563.

45. Suffat LP, Mondini G, Demaria F, et al. A proposal for thyroid surgery: criteria to identify the references of endocrine surgery. Updates Surg. 2017; 69(4): 431-434, doi: 10.1007/s13304-017-0487-z, indexed in Pubmed: 28975541.

46. Adam MA, Thomas S, Youngwirth L, et al. Is There a Minimum Number of Thyroidectomies a Surgeon Should Perform to Optimize Patient Outcomes? Ann Surg. 2017; 265(2): 402-407 doi: 10.1097/SLA.0000000000001688, indexed in Pubmed: 28059969. 